\title{
Spatial production and spatial dialectic: Evidence from the New Urban Districts in China
}

\author{
ZHUANG Liang ${ }^{1}$, 'YE Chao ${ }^{1}$, HU Senlin² \\ 1. Key Laboratory of Geographic Information Science (Ministry of Education), School of Geographic Sciences, \\ Shanghai Key Laboratory for Urban Ecological Process and Eco-restoration, Institute of Eco-Chongming, \\ East China Normal University, Shanghai 200241, China; \\ 2. School of Urban and Regional Science, East China Normal University, Shanghai 200241, China
}

\begin{abstract}
New Urban Districts (NUDs) are the important spatial carriers to promote urban expansion or transformation. Since the 1990s, they have been playing a more and more crucial role in China's urbanization. For NUDs in the strict sense we found that: $96 \%$ to the east of $\mathrm{Hu}$ Line; $56 \%$ within the municipal districts; $64 \%$ within $36 \mathrm{~km}$ from their every city center and below the area of $423 \mathrm{~km}^{2}$. The regional distribution follows significant spatial difference as "Eastern Region (50\%) - Central Region (42\%) - Western Region (8\%)", and the provinces with the largest number of NUDs are Guangdong, Henan, Zhejiang, Liaoning, and Jiangsu. Furthermore, their interesting constructed process highlights the typical characteristics of spatial production and spatial dialectic. This paper uses the theory of the production of space, and discovers that the growth of NUDs is a rapid ternary dialectical process of spatial production: "representations of space" is guided by the top-down governmental power; "spatial practice" is reflected in the hierarchical and regional difference of spatial elements, such as the type, pattern, distance and area of NUD; "spaces of representation" embodies the tension between governmental power and urban development rights, as well as the countermeasure mechanism. The extensibility of spatiotemporal sequences ensures the unity and continuity of spatial (re)production of NUDs. However, this is also facing a series of challenges like the management coordination of administrative division and the increasing unbalanced or inadequate development. Thus, critically rethinking the evolution of NUD is the key basis for achieving sustainable urban renewal and regional orderly development in the new era.
\end{abstract}

Keywords: new town; urbanization; production of space; ternary dialectic; administrative division; development zone

\section{Introduction}

NUD is a very important phenomenon and concept in China. With the evolving urbanization, its development is to be more and more rapid and widespread. The concept of NUD can be

Received: 2019-04-17 Accepted: 2019-06-20

Foundation: National Natural Science Foundation of China, No.41571138, No.41771171, No.41871143, No.41961029

Author: Zhuang Liang (1989-), PhD Candidate, specialized in urbanization and production of space, urban management and administrative division. E-mail: zhuangliangboy@163.com

*Corresponding author: Ye Chao (1978-), PhD and Professor, specialized in geographical thought, urbanization and cultural geography. E-mail: yeover@163.com

www.geogsci.com www.springerlink.com/content/1009-637x 
traced back to the "garden city" which is essentially a combination of city and township (Howard, 2007). In view of the ideas of sustainable and composite development, it has gradually become an inevitable choice for many countries or regions. Governments usually have a large number of institutional, planning, and policy tools that are key factors influencing NUDs (Lee and Shin, 2012). In these new development zones, the transformation of land use in the suburbs often directly leads to cities' spatial expansion. However, because of the "mismatch" between conceptual goals and planning practices (Wang and Heath, 2010), NUDs also encounter various setbacks, such as socio-spatial segregation, excessive urbanization, environmental degradation and other unsustainable development issues (Firman, 2004; Song, 2005; Lau and Chiu, 2013; Abubakar and Doan, 2017). As the ultimate decision maker and participant of NUD establishment, government plays a powerful role in the expansion of urban emerging spaces (Ma, 2002). By May 2016, the number of NUDs in China in the broadest sense has exceeded 3500 (Feng, 2016). But the terms "new town" and "new district" are commonly mixed, so it is urgent to define the NUD in a specific sense through the definition of indicators as the main target for dialysis the development logic of China's urbanization. Obviously, large-scale and rapid traditional urbanization in China has put multiple pressures on the ecological environment, infrastructure and natural resources (Chen et al., 2010). In future, the national strategy of new-type urbanization should emphasize the urban development appeals of people-oriented and urban-rural coordination (Chen et al., 2013; Long, 2014; Chen et al., 2016). In which, NUD will be a vital spatial carrier and support for the urban agglomeration planning in the new-type urbanization (Zhang et al., 2017). Since the 1990s, major cities have established district-or-county-level and even higher-level NUDs what have spread to 30 provinces in Chinese Mainland except Beijing (Zhuang et al., 2019). This growth process is full of ups and downs. Despite the emergence of high-level warnings and normative constraints in recent years, the intensive establishment of state-level NUDs remarks the importance of the central government in shaping urban transformation through territorial reforms (Martinez, 2018; Kuang et al., 2018). And the urban expansion of municipal districts is particularly prominent. Therefore, the spatial production of NUDs has developed into an unavoidable phenomenon and problem.

Research on the relationship between NUD and urbanization is receiving more and more attention and progress. The policy guidance for regional population mobility has reconstructed the urban system and spatial pattern (Liu et al., 2015), so China's social informality has been created by the "urban-rural dual structure" (Wu et al., 2013; Ye et al., 2018). By improving the quantity and quality of small and medium-sized cities, it will effectively eliminate the dual-track structure of urban-rural development and enhance the synergistic development capacities (Liu et al., 2015; Ye et al., 2019). In this context, NUDs came into being and became one main trend of city development in China, which also spawned new urban problems (Su et al., 2014). The domestic research topics on NUD have gone through three major stages: foreign theories, development zone, and comprehensive NUD. Of course, some studies have already touched on the relationship between spatial production and NUD: spatial production is an important way of capital proliferation in a specific period (Brown, 2019), and NUD is a main spatial carrier for "spatial fix" of surplus capital during the process of capital accumulation. Consequently, the internal structural adjustment of capital accumulation cycle has brought different types, patterns and characteristics to NUDs. With 
introduction of theories such as scale reconstruction and spatial production, the state-level NUD is interpreted as a specific scale reconstruction tool under the central government decision-making (Fu and Zhang, 2018). Starting from the theory of spatial production, power and capital promote the new urbanization and also cause the alienation of urban spaces (Meir and Karplus, 2018; Ye et al., 2019). Therefore, it is necessary to further understand the special logic of capitalization of space. China's urbanization has typical "endogenous" characteristic and is strictly influenced by administrative forces (Cartier, 2016). On the whole, the theoretical interpretation of spatial organization such as NUD is relatively lacking based on the combination of spatial production and administrative division (Ye et al., 2014; Chen et al., 2015; Fang et al., 2016). Under the people-oriented concept of new-type urbanization, we need to reorganize and rethink the NUD and its transformation with power and capital in space.

In short, current researches on NUD mainly focus on its general form of spatial organization. In theory, it tends to explore the city-industry integration, functional orientation, management system and development model, and pay less attention to the characteristics of specific spatial unit (Che, 2017; Qiu et al., 2017). Therefore, the number and scale-expansion of NUDs need new theories to explain and respond. In the empirical aspect, most researches are based on the cases of some national or local new districts, and gradually pay attention to land operation, administrative governance and local state restructuring (Yang et al., 2015; Li and Chiu, 2018), but lack of profound analysis on the evolutionary characteristics of nationwide NUDs and their internal logic (Zhang and $\mathrm{Wu}$, 2008; Xue et al., 2013; Li, 2015; Fu and Zhang, 2017; Shen and Wu, 2017). Therefore, we must focus on this spatial organization of NUD, and through theoretical transformation to achieve critical thinking on the evolution of time and space pattern. The production of space is a critical theory for explaining the NUD. It is proposed by Lefebvre; whose core category is the trinity of space. Its methodology is "ternary dialectic of space", ethical appeal is justice, essential attribute is political, and dominant trends are urbanization and globalization (Lefebvre, 1991; 2009). After him, Harvey and Smith have given a good inheritance to the theory (Harvey, 1973; 1985; Smith, 2010). In a word, the production of space refers to the process of interaction and influence between capital, power, class and space (Zhang, 2000; Ye et al., 2017; Ye et al., 2019). NUD can be understood as a kind of "spatial fix" of capital, or an effective solution for continuous accumulation (Harvey, 1981). This highlights the characteristics of spatial production in which multiple elements playing each other.

We make a new interpretation of the evolution process of China's NUDs from the theoretical perspective of spatial production. NUD is an important practice and carrier of the new-type urbanization strategy. Along with rapid urbanization, although study on NUD has been carried out, the problems about process and mechanism of spatial production have not yet been clarified (Zhuang, 2017). This paper is based on the research idea of "model construction - positive analysis - logical abstraction": firstly, try to propose a conceptual model of spatial production in China's NUDs; secondly, analyze their spatiotemporal pattern and evolution path; finally, use the conceptual triad to reveal the logic of spatial production of NUD. We aim to provide a theoretical exploration and empirical path for the relationship between urbanization and spatial production. 


\section{Research data and methods}

\subsection{Research object and description}

(1) Data sources. The data acquisition process of this study is as follows: According to concept definition, the policy texts from the governments' official websites of 31 provincial-level administrative regions and 334 prefecture-level ones in China are analyzed, and 224 NUD samples from 159 cities are screened (Figure 1). The data such as the time, area and organization are mainly from the official websites of 224 NUDs, as well as the statistical yearbooks of relevant cities, including some field research data. The deadline for data statistics is at the end of December 2016. Notably, time refers to the actual establishment time of NUD management organization, aiming at circumventing some of the planned or pending immature NUDs. In addition, the spatial distance of the management organization from its upper administrative center is derived from "Ranging Tool of Baidu Map" for the linear distance measurement of 224 NUDs and the 159 cities to which they belong. Again, the spatial coordinates are obtained from "Baidu Coordinate Picker" for geolocation of all NUDs' management organizations. The data of county-level administrative division is approved with reference to the "National Administrative Division Information Inquiring Platform", and the map of China's administrative divisions comes from "National Geomatics Center of China".

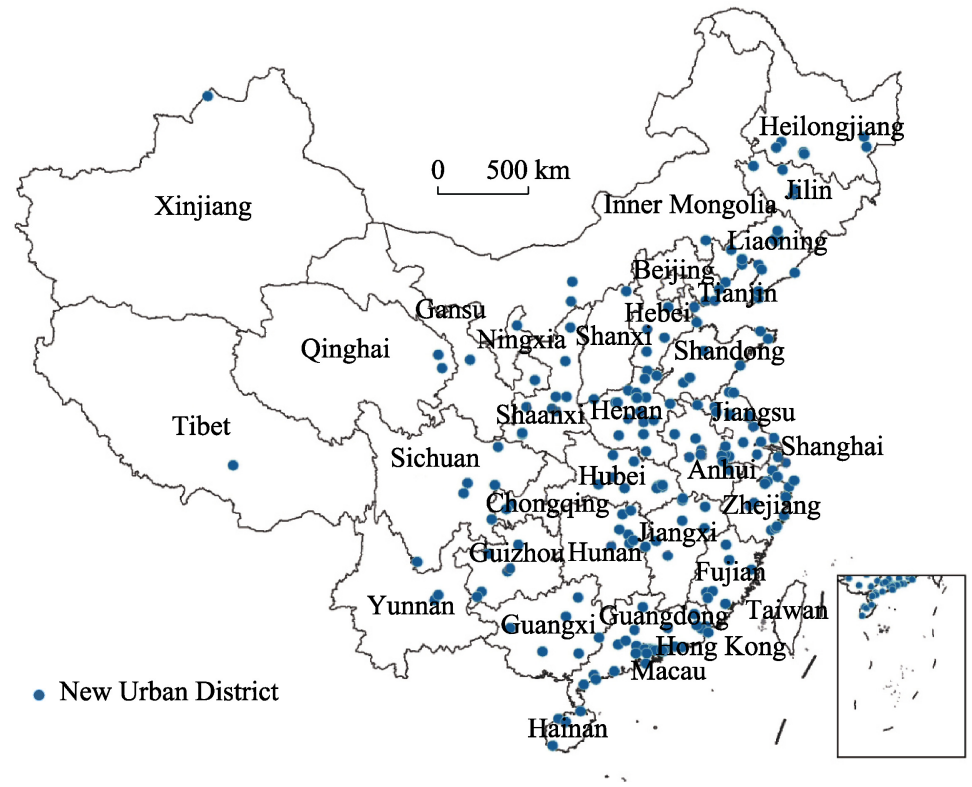

Figure 1 Spatial distribution of 224 NUDs in China during 1993 to 2016

(2) Concept definition. NUD is a long-standing term, and the academic community has yet to reach a unanimous statement. We define it in a narrow sense as: an independent new urban area that integrates production and life and has a clear management scope, considerable management authority and special management system based on urban development demands; a solution to the function of city center or the expansion of urban strategy; a modern space unit that highlights the functional composite features of city. Meanwhile, sample selection depends on the following indicators: first, it has the corresponding independent 
regulatory body; second, it has an independent government or a dispatched agency established by a government at or above the prefecture level; and third, its management system specifications are at or above the county level; fourth, it participates in the escrow, custody or direct management of grassroots administrative divisions such as villages and towns; fifth, it has the strategic positioning characteristics that reflect the city's composite function; sixth, its management organization (management committee or government) has an official website.

(3) Research area. In terms of time, the establishment time of NUD is mainly based on the actual listing of its management organization, and the statistical range is from 1993 to the end of 2016. In terms of space, it involves China's 31 provincial administrative regions that do not include Hong Kong, Macao and Taiwan. At regional level, the proportion of NUDs in the three Regions (Eastern, Central and Western) is 50\%, $42 \%$ and $8 \%$ respectively. At provincial level, the provinces with a total number of NUDs accounting for more than $7 \%$ are Guangdong, Henan, Zhejiang, Liaoning, and Jiangsu. This paper divides the development of NUDs into three stages (Figure 2). First is the Low-speed Growth Stage (LGS). It is characterized by a low growth and a slow rate, which is at a low-speed growth level before 2002 and a high volatility and low-speed growth at a later period. Next is the High-speed Expansion Stage (HES). The number achieved rapid growth and its rate is about 2 times higher than the highest value in the first stage. Its quantity also experienced a large expansion and the average annual increment is about 7 times in the first stage. And the annual number and increment are respectively the highest in history and are increasing year by year. Final is the Slowdown Adjustment Stage (SAS). The establishment of NUD quickly fell to the first stage level in a short period, and the annual average increment is less than $1 / 3$ of the HES, and only twice the LGS. At the same time, under the trend of continuous "going down", state-level ones have ushered in a rapid increase. Besides, the development of NUDs is not a process of "increasing growth". It has also undergone cancellation or transformation and experienced adjustments in terms of growth rate or establishment ways in recent years.

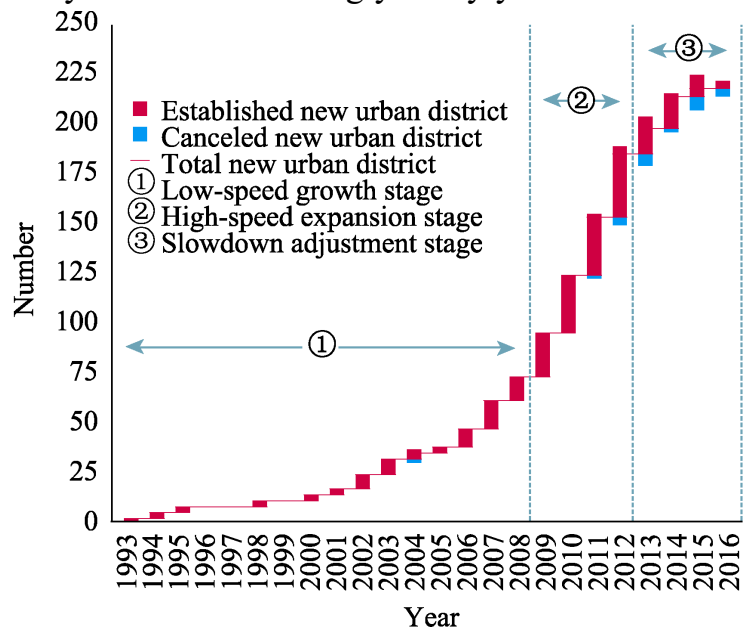

Figure 2 The stage evolution of NUDs in China

\subsection{Research framework and method}

(1) Spatial model. The construction of NUDs in the process of urbanization is closely related to the reconstruction of urban spaces in China. It is necessary to establish a spatial evolution model under the influence of power. Based on the theory of spatial production, this paper designs a model that reflects the construction of NUD being a three-dimensional, multi-factor interaction process of spatial production (Figure 3): first, it has different functional characteristics from the traditional development zones; second, it is a spatial superposition process that follows the evolution of "development zone - NUD - administrative district"; third, it has different management systems and spatial setting types; fourth, its estab- 
lishment and development is a bidirectional process of "top-down" and "bottom-up" (Zhuang and Ye, 2018). Under the transformation demands of local traditional development models, diversified single functional zones need to be transformed into integrated ones. In the meantime, the traditional models and gradient strategies have exacerbated regional imbalances. At the national level, a new set of regional growth poles needs to be rapidly built through new spatial expansion models to promote the orderly development between regions. Thus, under the two-way effect of top-down and bottom-up, governments

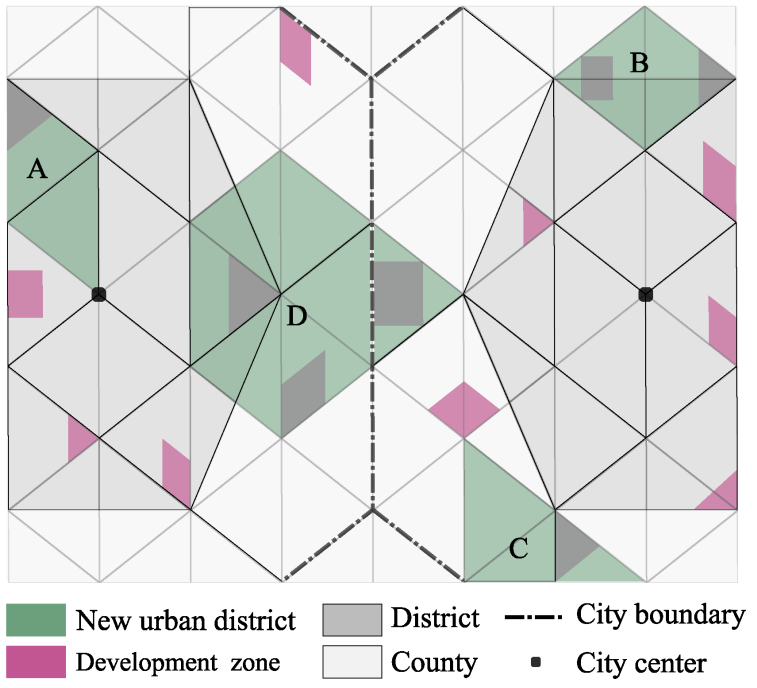

Figure 3 The basic spatial model of NUDs in China

at different levels will set up new districts and give different development orientations. In addition, the pioneering development privileges have created more new spaces for local government-led urban expansion. Dominated by governmental power, NUD is a rapid process of spatial production that integrates the characteristics of "spatial evolution of complex functions", "centralized urban expansion", "multi-dimensional spatial superposition" and "strategic adjustment of regional development".

(2) Method. The density estimation method of Kernel is applied significantly in the agglomeration analysis of spatial point data and has a good performance in revealing the distribution characteristics of point groups in NUDs. Points located within the search radius will be assigned different weight values, and the closer to the grid search center, the greater the weight value will be assigned. This method mainly achieves the spatial visualization of point distribution by transforming the discrete "points" into a continuous "point group" density map. Let the density value at $p$ be $\lambda_{h}(p)$, then the estimated value formula is as follows:

$$
\lambda_{h}(p)=\sum_{i=1}^{n} \frac{3}{\pi h^{4}}\left(1-\frac{\left(p-p_{i}\right)^{2}}{h^{2}}\right)^{2}
$$

where $p$ is the location of NUD point to be estimated, $p_{i}$ is the $i$-th point position in the circular search area with $p$ as the center and $h$ as the radius. The selection value of $h$ will directly affect the smoothness of point distribution density estimation. In order to make the results year-to-year comparable, this paper sets the same search radius and cell size.

\section{Characteristics of spatial production in China's NUDs}

\section{1 "Representations of space": Construction of space by power}

The "representations of space" refers to the conceptualization of space, or the allocation of power, knowledge, and space. The materiality of mainstream social orders is contained in it and is thus justified (Gregory, 1994). In the practice of NUD, it is primarily represented by the abstract designs of planning ideas by governments and their appointed experts, which is 
actually the construction of power for space. Therefore, we explained the "representations of space" of NUD based on strategy formulation, policy design, administrative department, and dispatched agency.

(1) Strategy formulation and policy design. The development of NUD has always run through the construction of spatial powers between different levels of government. Their administrative means include the formulation and restriction of many strategic plans and policy texts, such government-led statutes imply the interests of different discourse rights. Initially, local governments generally promote the scale expansion of cities through industrial construction of various development zones. With the large number of single-function development zones, their functional appeals of social services and management have become increasingly prominent. It is urgent to take some more comprehensive measures to integrate functions in the development zones, especially to solve some institutional bottlenecks. However, the traditional regional development strategies have made regional differences increasingly serious. We must choose more comprehensive spatial carriers as new growth poles to drive urban or regional development. At the same time, local governments will begin large-scale NUD planning, and constantly pursued higher administrative levels in order to obtain more development privileges or policy supports. In this fierce declaration process, NUD with better foundations or more potentials will be awarded the title of "state-level". NUD has thus become the main mode of transformation of the development zone, and an important way for the urban spaces to carry out a new round of strategic expansion.

(2) Administrative department and dispatched agency. NUD reflects the government's top-down power allocation. Relying on the spatial layout of regional strategies, the State Council or local governments will selectively instruct specific areas to prepare for the construction of NUDs. If the approval process is successfully passed, it will be officially awarded the title of "NUD" at the corresponding level, and a strict top-down administrative management system will be formed. There are both the macro guidance of top management departments and the dispatched management of local governments' high-level configuration: first, NUD is usually approved by the government departments of higher authorities and is mainly supervised and guided by the National Development and Reform Commission (NDRC), and adopts a step-by-step periodic reporting mechanism; second, government departments (involved in land, environmental protection, and housing construction) shall comply with the development of NUDs in accordance with their establishment criteria and review procedures; third, provinces (and autonomous regions or municipalities) need to set a coordination mechanism to coordinate and solve major problems in the development of NUDs. The main leaders of NUD management agencies are often directly or concurrently appointed by provincial or municipal authorities. In addition, the management committee is often used as the dispatched agency of provincial or municipal government and is responsible for economic development, urban construction or social management in accordance with the county-level or above organizational standards. At different stages, NUD will also adopt different administrative management systems according to its own actual conditions, which can be roughly divided into three types: the first type is Management Committee. As a dispatched agency of higher-level government, it largely exercises the management authorities of development and construction in the district, while its social affairs are basically the responsibility of the administrative district where it is located; the second one is Combination 
of Administrative Region with NUD. Namely, the management committee and its administrative district government implement a joint office of "a set of people and two brands"; the last type is Government. The NUD was approved by the State Council to establish a first-level government and was given full administrative authorities. Therefore, in the early stages, most of the current NUDs adopt the management committee type. In the more mature stages, it is necessary for NUD to break through the constraints of the original administrative district to undertake more construction, management or service functions, and then gradually establish a government to achieve the transition to an independent administrative district.

\section{2 "Spatial practice": Shape of space by power}

The "spatial practice" refers to the space-time routine and spatial structure (such as places and paths) of social life to achieve production and reproduction. It actually corresponds to the process by which power shapes the real space of physical form. There are four aspects: the production of space, the dominance and control of space, the occupation and use of space, the accessibility and distance of space (Harvey, 1989). Therefore, this paper selects the distribution pattern, combination type, center distance and area size as the four practical references of the "spatial practice".

(1) Distribution pattern and combination type. On the one hand, the evolution study of spatiotemporal patterns is conducive to revealing a series of phased processes and outcomes of NUDs, which are related to government behavior, land use, resource environment, social life and many other aspects. Through the Kernel analysis in the node years, it is found that NUDs have significant spatial differentiation characteristics (Figure 4): (a) By 2004, NUDs were distributed evenly in the eastern and central provinces of the Yangtze and Yellow River basins, but it had not yet been established in South China. (b) By 2008, NUDs were gradually launched in many provinces in the east of the Hu Line, which were most significant in the eastern coastal areas and had the highest density in the Yangtze River Delta (YRD). During the period, all the three provinces of South China began to set up NUDs in 2007. (c) By 2012, the NUDs distributed to the west of the Hu Line accounted for about $5 \%$ of the total. At this time, the spatial agglomeration characteristics of the national scale are particularly obvious, and there are high-density clusters such as "Jiangsu-Zhejiang-Shanghai-Anhui", and sub-clusters in Henan and Guangdong, as well as the largest spatial agglomeration belt running through the north and south. (d) The number of NUDs existed in 2016 is 27\% higher than that in 2012, and the major trend of clusters and belts is further strengthened. Moreover, the number of west of the Hu Line accounted for only 4\%, and the regional differences in spatial distribution continued to widen. On the other hand, to explore the combination relationship between NUD and municipal district(s) or related county(s) is easy to grasp the spatial evolution logic of NUD in the process of urbanization. The spatial arrangement in NUDs can be classified into four types (Figure 3 and Table 1). The combination of A-type is mainly based on single "district", which is often expressed as the "upgrading" of NUD within the city's jurisdiction and the gradual "expansion" of the administrative divisions such as withdrawing county (or county-level city) and to set district. The combination of B-type mainly includes: district + county, district + county-level city, district + county + county-level city, district + autonomous banner. And the combination of C-type is 

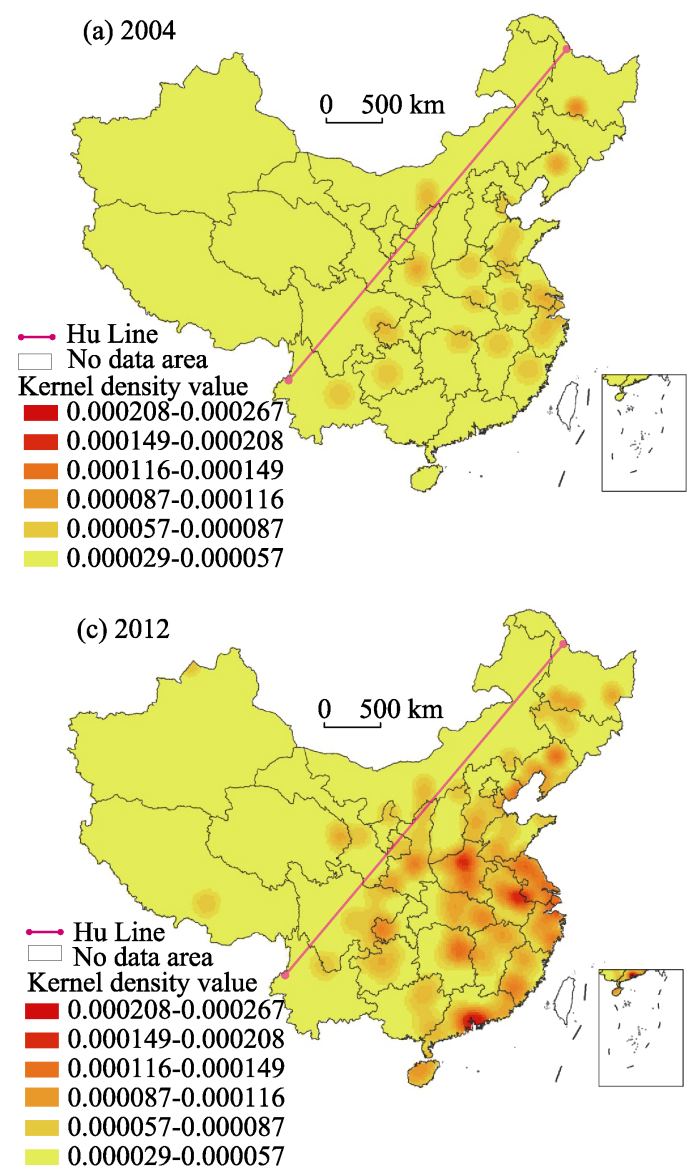

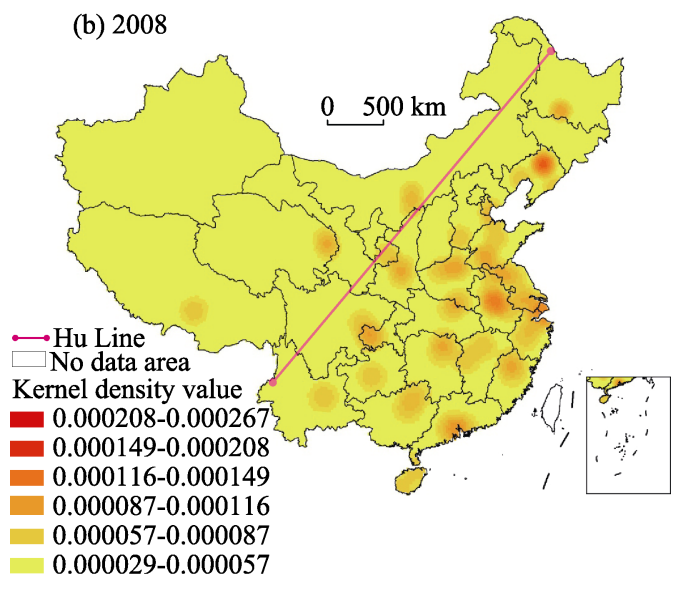

(d) 2016

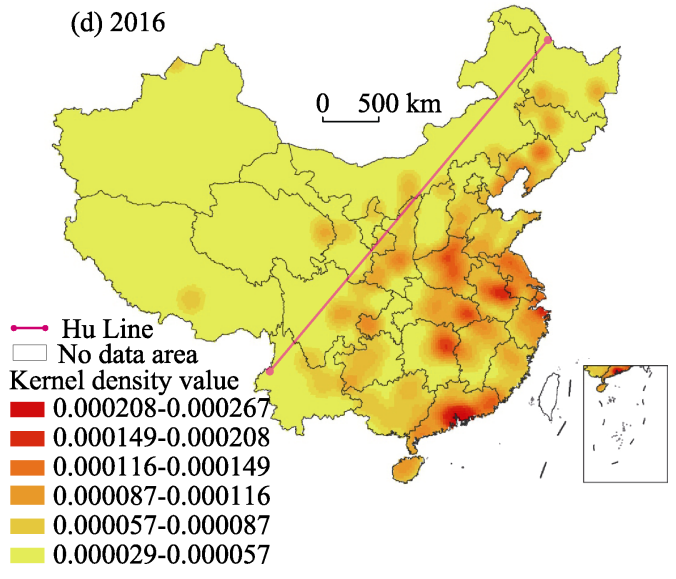

Figure 4 Kernel analysis of spatial layout of NUDs in China during 1993 to 2016

Table 1 Types of spatial arrangement in NUDs

\begin{tabular}{clc}
\hline Type & \multicolumn{1}{c}{ Specific meaning } & Proportion (\%) \\
\hline A & Composed of single district(s) of the same prefecture-level city (or municipality) & 56 \\
B & Composed of district(s) and county(s) of the same prefecture-level city (or municipality) & 20 \\
C & Composed of a single county(s) of the same prefecture-level city (or municipality) & 21 \\
D & Composed of district(s) and county(s) of the different prefecture-level city (or municipality) & 3 \\
\hline
\end{tabular}

as follows: county, county-level city, county + county-level city, autonomous county. Besides, the D-type representing the regional cooperation between cities accounts for about $3 \%$, and its combination ways mainly include: district + county + county-level city, district + county. It can be seen that the type evolution of "A-B-C-D" suggests the continuous breakthrough of NUDs at all levels in urban expansion, that is, gradually realize the co-construction from the city center to the outer suburbs and even adjacent cities in the spatial distance. Therefore, this also illustrates the inherent demands of the prefecture-level administrative region (or municipality) in NUD for urban expansion in the urbanization process.

(2) Center distance and area size. Through the establishment of NUD, government has 
constructed a hierarchical practice mode of nested geographical distance and space scale. With the increasing planning scope of NUD, the location of its regulatory agency will gradually realize the extension of power allocation from municipal districts. Based on the mutual distance between the regulatory agency and its superior administrative center, this paper uses "Jenks" tool of ArcGIS10.2 to realize cluster analysis and spatial visualization of all distance data (Figure 5, left): the NUDs of Grade-I account for nearly $60 \%$ of the total, and their spatial distribution in the central and western regions is relatively balanced and mainly concentrated in the eastern and central provinces between Yangtze and Yellow River. More than $96 \%$ of regulatory agencies are located within the municipal districts, having administrative convenience and efficiency. In which, several provincial capitals with only one district often locate its NUD outside its municipal district, while the regulatory agency is located within it. This tendency to "upgrade NUD to district" also symbolizes the centrality of management, so the inconsistency between NUD limits and its regulatory agency occurs within a short distance. The proportion of Grade-II is more than $1 / 4$ and there are differences in the spatial distribution of the central and western regions, which are obviously concentrated in the Pearl River Delta (PRD), YRD and the Bohai Rim. Meanwhile, more than 1/2 of management agencies in the closer range are located within A-type NUDs, continuing a "point-to-face" consistency of the regulatory agency and NUD range within the city's municipal districts. Among them, 29\% of NUDs' regulatory agencies are not located within the scope of municipal districts, so the NUDs outside the municipal districts have a certain space-consistency and management-independence. The regulatory agencies of Grade-III and Grade-IV show more obvious differences in spatial distribution. Grade-III is spatially distributed in PRD, YRD and the Beijing-Tianjin-Hebei Region on the eastern coast, while Grade-IV are scattered in Hebei, Liaoning, Hubei, Fujian, Hainan, and other provinces. These long-distance regulatory agencies often have the characteristics of "coastal trend" or "provincial boundary". The area of traditional new towns in the world is mostly within the range of tens of square kilometers, while that in China is generally larger, even exceeding the area of a county or district in the region (Tanabe, 1978; Khamaisi, 2011; Colenutt et al., 2017). As a result, NUDs with different area sizes and spatial distributions are significantly different (Table 2).

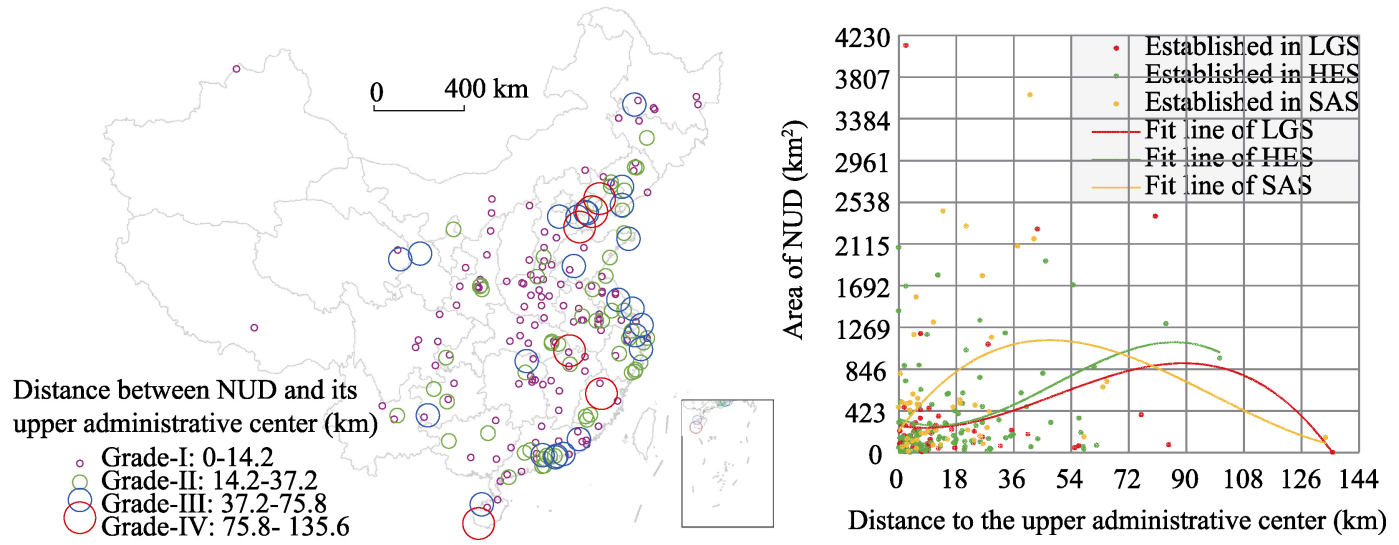

Figure 5 The spatial distribution of distances between regulatory agency and upper administration center and the changing trend of spatial elements of NUDs in China during 1993 to 2016 
Table 2 Area scale of NUDs

\begin{tabular}{|c|c|c|c|c|c|}
\hline Scale & Feature & Area $\left(\mathrm{km}^{2}\right)$ & $\begin{array}{c}\text { Number ratio } \\
(\%)\end{array}$ & $\begin{array}{c}\text { Area ratio } \\
(\%)\end{array}$ & $\begin{array}{c}\text { Average area } \\
\left(\mathrm{km}^{2}\right)\end{array}$ \\
\hline Small & The smallest size, the largest number. & $0-160$ & 47.8 & 8.7 & 77 \\
\hline Medium & The smaller size, the larger number. & $160-419$ & 22.8 & 13.7 & 255 \\
\hline Large & The largest size, the smallest number. & $419-960$ & 17.0 & 23.6 & 588 \\
\hline Massive & The largest size, the smallest number. & $960-4132$ & 12.1 & 53.8 & 1887 \\
\hline
\end{tabular}

The small-scale NUDs are spread over most provinces. Since the smallest size is common in the initial stage of urban expansion, they are more evenly distributed in the eastern, central and western regions. Most of the medium-scale NUDs are distributed in the central and eastern coastal areas. Since the smaller size is often present the development stage of urban expansion, the distribution tends to shift to the central and eastern regions. The most important feature of large-scale NUDs is that they are all located in the east of Hu Line. Since the large-scale planning is usually based on the relatively mature stage of city development, the distribution is more consistent with the regional urbanization level. The massive-scale NUDs (including more than $3 / 5$ state-level ones) are primarily distributed in the eastern coastal areas with high urbanization levels. With the emphasis on planning scope and regional strategy, the types of administrative districts spanned by massive-scale NUD are also more complicated. In addition, it is found by a scatter plot of the phased distance and area data (Figure 5, right): most of NUDs are concentrated within a distance of $18 \mathrm{~km}$ and with an area of $423 \mathrm{~km}^{2}$ or less, and it is gradually characterized by a more significant "closer-distance, larger-scale" planning.

\section{3 "Spaces of representation": Reconstruction of space by power}

The "spaces of representation" refers to the confront spaces or struggle places, which stem from the privacy and underside of social life, and the critical art of "questioning the practice of mainstream spaces and spatiality with imagination" (Gregory, 1994). In NUDs, this is externalized into the social relationship between bodies in our daily life, reconstructing the spaces with power through time and use. Therefore, we aim to interpret the "spaces of representation" from four aspects: power game, power appeal, development disorder, and planning early-warning.

(1) Power game and right appeal. Due to the lack of uniform standards and supervision mechanisms, the NUDs instructed or issued by prefecture-level cities occupy the largest proportion, and the power relationship within their spatial competition is more complicated. NUD fully embodies the spatial power game between the governments at all levels in urbanization. In this process, the government seat as a central place of power plays an important role. Since the development pressures of old districts and their adjacent counties, many cities will face the problem of urban district expansion and administrative center migration. Most of NUDs have become important transitional spaces for cities before the relocation of government seats. When the government offices are successfully relocated, some NUDs will be withdrawn or converted, while other reserved ones will continue to assume responsibility for urban construction, and more than $13 \%$ involve the migration of prefecture-level or provincial-level administrative centers. In particular, some even moved the prefecture-level ad- 
ministrative center from municipal district to farther county. It shows that the local government is so powerful in exercising administrative means. At the same time, the construction of NUD has also highlighted the local struggles for urban development rights. First of all, the built-up area within the municipal districts is constantly saturated or the urban expansion is limited due to the "protection of resources and cultural relics". Therefore, the reconstruction or protection of old towns and the government transfer became one original intention of NUD establishment. Secondly, NUD is also the demand for the transformation and development of traditional resource-exhausted cities, and the western mountain cities are often faced with bottleneck constraints of linear cities due to geological terrain limitations. Again, the distribution of rivers, lakes and seas is another factor that affects the spatial layout of urban centers. As a spatial strategic form, NUD directly maps the future orientation of city development. In samples, NUDs with waterfront distribution are more than $1 / 2$ and mostly named after the rivers, lakes and seas. Especially under a series of strategic guidance, the demands of waterfront development, cross-river development and basin co-development have been quite remarkable. For example, co-development can not only expand the main strength of immature areas, but also can learn from each other and achieve regional division of labor between regions.

(2) Development disorder and planning early-warning. The surge in NUDs has stimulated and formed some developmental disorders. Firstly, as the long-term process of population-urbanization lags behind land-urbanization, the extension of urban spaces has emerged as a prominent phenomenon such as "ghost city", and similar problems even exist in the state-level NUDs such as Lanzhou New District. Now, more than $90 \%$ of the prefecture-level cities are planning NUDs and some of them have several times the total area of their respective built-up areas. Next, the NUDs also bring potential challenges and difficulties in administrative division work: many cities have promoted the transformation of NUDs into administrative districts by means of withdrawing counties or county-level cities, which will inevitably produce a strong demonstration effect. Moreover, the number of sub-level NUDs has also increased, and the NUD has gradually strengthened the custody and escrow of villages and towns, which have created new difficulties in administrative division management. Furthermore, the construction boom of NUD is still the key development orientation of various cities, and there are considerable NUDs that are under construction or have not yet established formal management agencies. More urban strategies or plans are also carrying out high-standard ideas for NUDs, especially in the "13th Five-Year Plan" of some provincial or prefecture-level cities. Among them, most plans have been put into action, and the goal which is high and unrealistic has become a problem that cannot be ignored. Therefore, the establishment of NUDs in recent years has been subject to high-level warnings and is clearly bound in relevant documents. Planning early-warnings ensure that the problem of out-of-control is dealt with on the basis of scientific analysis such as data and facts. The approval of NUD mainly follows the processes such as "NDRC - Ministry of Housing and Urban-Rural Development (MOHURD) - Ministry of Natural Resources (MONR)": firstly, it strives to be included in the regional development plans by NDRC to form a concept of "NUD" and obtain corresponding policy supports; secondly, NUD will be planned and compiled for urban and rural construction by MOHURD; finally, the MONR needs to coordinate and weigh the indicators for construction land, which is also the key link for the legal ap- 
proval of NUD. In addition to the above-mentioned norms, it also involves other factors such as urban hierarchy and government officials. In recent years, MONR has also tried to promote the implementation of the "national land planning control" system. That is to say, the NUD that conforms to the national planning is basically approved, otherwise it will be rejected. Therefore, planning early-warning should guarantee the binding effect of relevant normative documents and strictly control the approval of land use in NUDs.

\section{Discussion: Logics of spatial dialectic in China's NUDs}

To study the growth of China's NUDs from the perspective of spatial production, it should follow the dialectical and unified thinking of "time (process) - space (pattern) - society (mechanism)", and then establish a concise logic framework (Figure 6). In which, the representations of space, spatial practice and spaces of representation are the core categories of Lefebvre's "ternary dialectic of space" (Lefebvre, 1991). There is a non-linear order between the three, but a mutual generation and construction relationship with multiple dialectic and tension. The "spaces of representation" and "representations of space" are antagonistic by "dominance space" and "opposition space" respectively, but the two are also intertwined. That is, the former helps the dominator to recognize the situation and position to seek the path of resistance, and the latter is the place where the dominant interests and resistance forces fight together and misappropriate (Wang, 2009). Correspondingly, the "spatial practice" lies between the above two and makes them mutually interconnected and distinct. It is the space-time structure in which space can be produced and reproduced, which respectively supports the normal operation of "spaces of representation" and "representations of space". The "spatial practice" is a spatial process that promotes both production and reproduction with a certain continuity and cohesion (Gregory, 1994; Merrifield, 2006). Therefore, this framework not only performs spatial interpretation based on society and history, but also interprets society and history based on space, and highlights the dialectical unity between society, space and time through the

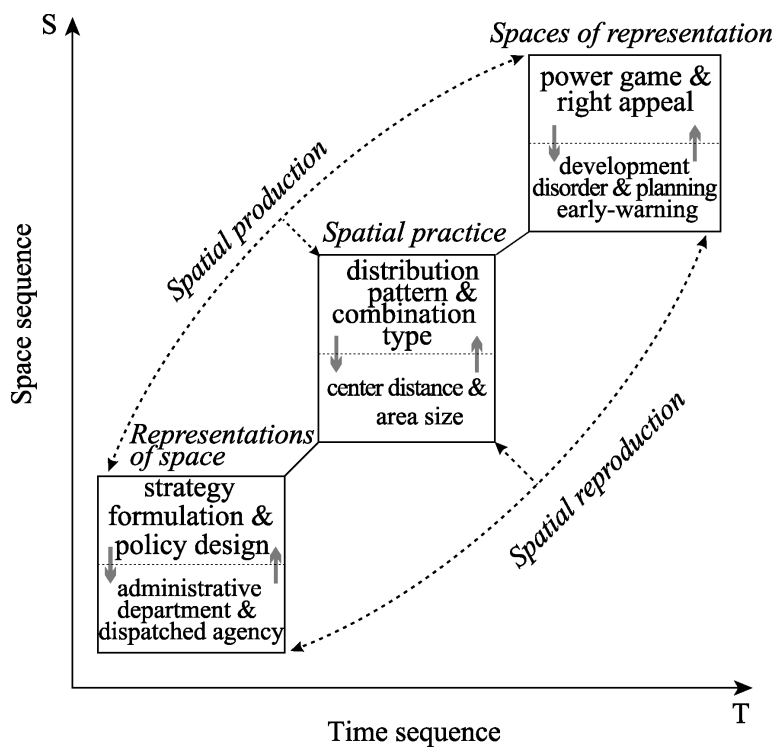

Figure 6 The spatial production of NUDs and its ternary dialectic spiral evolution of the three categories.

\section{1 "Trinity": Category and connotation}

The "representations of space" are mainly the conceptualized dominance space where various experts (and administrative agents and other agents or institutions) conduct norms and statutes through the symbolic system of language, discourse, text, and law. It is a spatial 
performance of the (political) power and ideology to achieve the concept of regularization (Elden, 2004; Merrifield, 2006). This category is embodied in the policy orientation and power allocation of NUDs at all levels of government, such as relying on scientists, planners, engineers to participate in strategy formulation, policy design to achieve textual planning for spaces, then through the administrative departments and their dispatched agencies further dominate the spatial control and benefit distribution in NUDs. In the process of developing NUD, government is not only the maker of space rules such as political texts and management systems, but also the biggest beneficiary of potential benefits such as land finance and socio-economy in space. It regards the NUD as a spatial tool to control, reconstruct and conquer the urban space. Thus, the government has the absolute right of discourse power. This is actually a top-down "discipline space" from the government perspective, which embodies the spatial representations of state orientation, government dominance and special policies in NUD model. This in turn allows officials, planners and developers to form meaningful abstract symbols (to guide spatial practice) (Gottdiener, 1993).

The "spatial practice" is largely used as a "material form" process for producing social spaces. It is not only a medium for sensing behavioral activities and experiences in the external physical environment, but also a construction result including production and reproduction, concept and execution, conception and life. Furthermore, it is an important way to generate, use and perceive space (Merrifield, 2006; Shields, 1999). This category is specifically represented by the distribution pattern and spatial combination type from the NUD level, and further microscopically focuses on the two large spatial elements such as the size (of NUD) and the distance (between the management agency and its superior administrative center). It aims to examine the practical characteristics of NUD in the process of passive obedience to government spatial planning from different scales. The process of spatialization of governments' powers is also a process of impairing the rights to urban development. For example, the unbalanced spatial distribution and management radius of NUD is always accompanied by the prominent differences in urban development rights within and outside the region, which laterally reflects the imbalance and inadequacy of spatial development. This is actually a kind of perceptual production of space, corresponding to the material relationship between the new growth pole and the spatial superposition that is produced and used in the evolution of NUD. Consequently, the practice of NUDs is repeatedly organized, restricted and promoted by structure (pattern-type-distance-scale), and structure is not only the medium of practice but also the result or product of practice, so it is embedded in or embodied in the practice of NUDs. It eventually exists and plays a role in the form of memory traces (Wang, 2009).

The "spaces of representation" primarily refers to the imagination originating from the private secrets of social life, and is a space for questioning and criticizing mainstream spatial practice while giving its symbol and meaning. It is also a spatial field that combines realistic imagination with practical thinking to create an anti-dominant order (Gregory, 1994; Soja, 1996). This category is embodied in the power game between local government departments at all levels and the struggle for development rights between local cities. The series of social effects generated by NUD under the "discipline" of power further stimulated the local struggle for urban rights. That is to say, the spatial planning of government powers is heterogeneous. Where the space rules fail, it is where the pursuit of production of "anti-discipline 
space". Therefore, the adjustment of administrative divisions and the planning of early-warning mechanisms have become the key means for government to carry out space adjustment and re-discipline. This is actually a kind of bottom-up production of "anti-discipline space", which is highlighted by the spatial struggles and counter-measures of spatial expansion, regional differences and functional integration of various development zones in the process of NUDs. This is in order to change the status of their subordinates or marginalization in the game (Soja, 1996).

\subsection{Spatial production and reproduction}

The interaction and dialectical unity of the above three categories is an important link and composition of the spatial production and reproduction process in NUDs. The reciprocal spiral advancement of "spatial traid" is the main way of spatial production.

The complementarity between strategic policies and departmental institutions consolidates the important rules or habits that are associated with governments at all levels in the urbanization system, and is a key tool for government power to guide spatial behaviors. Government-led model of NUD has its own fixed capital in terms of spiritual will, material practice, and social feedback. And the re-territorization and re-spatialization of capital will increase the time-space complexity of unbalanced development. This can be a superior resource under government actions, or it can be a constraint to behaviors. Again, government's own design and acceptance of the disciplined approaches has shaped its spatial behaviors, and the differential rent-driven benefits driven by land finance have produced geographic differences in the intensity of capital investment. Therefore, spatial allocation of government powers fundamentally reshaped the combined mode of urban spaces. Especially, when such disciplinary texts and management designs are increasingly losing the relevance of spatial practice within local political system, the claims of urban development will become more prominent.

Unbalanced geographic development requires a combination of changing spatial scales and political behaviors, as well as the differences and recurrence of power behind different scales. The unbalanced and inadequate spatio-temporal pattern of NUDs is being produced, shaped, adapted and reconstructed by the changing "political-economic" and "social-ecological" processes. The expansion of NUD size and the change of management distance highlight the important strategic significance of volatility and liquidity in the contemporary geospatial forms. Moreover, different actors and agents try to implement spatial planning behaviors by trans-administrative districts, thus realizing the upward shift and reconstruction of urban new districts at different levels such as "city-region-country".

NUD embodies the special policies pursued by specific powers in specific places. These power structures have obtained a lot of wealth interests and political discourse rights from spatial production. Meanwhile, NUD is facing development difficulties at different levels, scales and locations, such as limited capital, inadequate popularity, deficiency in management, debt risk, overcapacity, traffic congestion and ecological governance, environmental crisis and other urban issues. The tension between political powers and social rights is constantly being reshaped in the process of spatial production and reproduction in NUDs. Regional imbalances have created enormous resistance to governmental decisions that represent multiple sets of special interests. The established policies have obvious instability and 
imbalance. However, after the government regulates and intervenes in the spatial factors such as the number and size of NUDs, the imbalance is intensified. This makes the production of NUD space seem to be in a situation where it cannot be fundamentally repaired.

\section{Conclusion}

The development of China's NUDs is a typical process of spatial production. NUD is the main spatial organization form for promoting rapid urbanization, which has gradually become an important means of fierce competition between regions. 224 NUDs are located in 157 prefecture-level administrative regions. Among them, 96\% are distributed to the east of Hu Line, and $56 \%$ are completely within the city's municipal districts. In particular, $64 \%$ of NUDs are established within $36 \mathrm{~km}$ from their every city center and with an area of $423 \mathrm{~km}^{2}$ or less. It brings a new geographical imbalance, mainly in two aspects: the production of spatial scales and the production of geographical differences. Various governments dominate the spatial production of NUDs. Geographic space is regarded as the field of power game and rights struggle, and the new political or economic functions formed by administrative division have a dual impact on the spatial production of NUDs. There are also significant scale-level differences in the spatiotemporal evolution of NUDs. The essence of this is the interweaving process of power reconstruction and spatial reorganization, which ultimately leads to new imbalances or inadequate development.

NUD is a comprehensive functional district different from the traditional development zones, and it has a positive effect on promoting regional development and urban-rural integration. First of all, the vitality of small and medium-sized cities based on NUDs should be fully stimulated through administrative divisions and spatial governance in a timely manner, and the spatial structure and functional transformation of NUDs should be improved in the rational prediction of spatial distance and scale. Next, it is necessary to use high-efficient institutional innovation to regulate the power expansion of local governments, and promote an orderly and sustainable development of NUDs on the basis of respecting regional differences. In addition, the state or government departments need to achieve multiple synergies in the governance of NUDs, development zones and municipal districts through power constraints. In the new-type urbanization, NUD should highlight and support the rights to differentiate development. Only when the city is integrated into the system designs according to the fair and just life rights, the standardized and orderly spatial production mode between the practice subjects can be constructed on the basis of "people-oriented" urbanization in the new era.

\section{References}

Abubakar I R, Doan P L, 2017. Building new capital cities in Africa: Lessons for new satellite towns in developing countries. African Studies, 76(4): 546-565.

Brown J A, 2019. Territorial (in) coherence: Labour and special economic zones in Laos's border manufacturing. Antipode, 51(2): 438-457.

Cartier C, 2016. A political economy of rank: The territorial administrative hierarchy and leadership mobility in urban China. Journal of Contemporary China, 25(100): 529-546.

Che Y L, 2017. The expansion of cities and the ensuing limitations on the production of space. Sotsiologicheskie Issledovaniya, (7): 107-115.

Chen H, Wu Q Y, Cheng J Q et al., 2015. Scaling-up strategy as an appropriate approach for sustainable new town 
development? Lessons from Wujin, Changzhou, China. Sustainability, 7(5): 5682-5704.

Chen M X, Liu W D, Lu D D, 2016. Challenges and the way forward in China's new-type urbanization. Land Use Policy, 55: 334-339.

Chen M X, Liu W D, Tao X L, 2013. Evolution and assessment on China's urbanization 1960-2010: Under-urbanization or over-urbanization? Habitat International, 38: 25-33.

Chen M X, Lu D D, Zha L S, 2010. The comprehensive evaluation of China's urbanization and effects on resources and environment. Journal of Geographical Sciences, 20(1): 17-30.

Colenutt B, Schaebitz S C, Ward S V, 2017. New towns heritage research network. Planning Perspectives, 32(2): 281-283.

Elden S, 2004. Understanding Henri Lefebvre: Theory and the Possible. London: Continuum.

Fang C L, 2015. Important progress and future direction of studies on China's urban agglomerations. Journal of Geographical Sciences, 25(8): 1003-1024.

Feng K, 2016. China's New Town and New District Development Report. Beijing: Enterprise Management Publishing House China Development Press. (in Chinese)

Firman T, 2004. New town development in Jakarta metropolitan region: A perspective of spatial segregation. Habitat International, 28(3): 349-368.

Fu Y, Zhang X L, 2017. Planning for sustainable cities? A comparative content analysis of the master plans of eco, low-carbon and conventional new towns in China. Habitat International, 63: 55-66.

Fu Y, Zhang X L, 2018. Two faces of an eco-city? Sustainability transition and territorial rescaling of a new town in Zhuhai. Land Use Policy, 78: 627-636.

Gottdiener M, 1993. A Marx for our time: Henri Lefebvre and the production of space. Sociological Theory, 11(1): $129-134$.

Gregory D, 1994. Geographical Imaginations. Cambridge, MA: Blackwell.

Harvey D, 1973. Social Justice and the City. London: Edward Arnold.

Harvey D, 1981. The spatial fix: Hegel, Von Thunen, and Marx. Antipode, 13(3): 1-12.

Harvey D, 1985. The Urbanization of Capital. Oxford: Blackwell.

Harvey D, 1989. The Condition of Postmodernity. Oxford: Basil Blackwell.

Howard E, 2007. Garden Cities of Tomorrow. New York: Routledge.

Khamaisi R, 1998. Building new towns in the formation of a new state of Palestine. Third World Planning Review, 20(3): 285-308.

Kuang W H, Yang T R, Yan F Q, 2018. Examining urban land-cover characteristics and ecological regulation during the construction of Xiong'an New District, Hebei Province, China. Journal of Geographical Sciences, 28(1): 109-123.

Lau J C Y, Chiu C C H, 2013. Dual-track urbanization and co-location travel behavior of migrant workers in new towns in Guangzhou, China. Cities, 30: 89-97.

Lee Y S, Shin H, 2012. Negotiating the polycentric city-region: Developmental state politics of new town development in the Seoul capital region. Urban Studies, 49(6): 1333-1355.

Lefebvre H, 1991. The Production of Space. Oxford: Blackwell.

Lefebvre H, 2009. State, Space, World: Selected Essays (translated by Gerald Moore, Neil Brenner and Stuart Elden). Minneapolis: University of Minnesota Press.

Li J, Chiu L H R, 2018. Urban investment and development corporations, new town development and China's local state restructuring: The case of Songjiang new town, Shanghai. Urban Geography, 39(5): 687-705.

Li L Y, 2015. State rescaling and national new area development in China: The case of Chongqing Liangjiang. Habitat International, 50: 80-89.

Liu T, Qi Y J, Cao G Z, 2015. Spatial patterns, driving forces, and urbanization effects of China's internal migration: County-level analysis based on the 2000 and 2010 censuses. Journal of Geographical Sciences, 25(2): 236-256.

Liu Y S, Chen C, Li Y R, 2015. Differentiation regularity of urban-rural equalized development at prefecture-level city in China. Journal of Geographical Sciences, 25(9): 1075-1088.

Long H L, 2014. Land consolidation: An indispensable way of spatial restructuring in rural China. Journal of Geographical Sciences, 24(2): 211-225. 
Ma L, 2002. Urban transformation in China, 1949-2000: A review and research agenda. Environment \& Planning A, 34(9): 1545-1569.

Martinez M H, 2018. "National Level New Areas" and urban districts: Centralization of territorial power relations in China. Chinese Political Science Review, 3(2): 195-210.

Meir A, Karplus Y, 2018. Production of space, intercultural encounters and politics: Dynamics of consummate space and spatial intensity among the Israeli Bedouin. Transactions of the Institute of British Geographers, 43(3): 511-524.

Merrifield A, 2006. Henri Lefebvre: A Critical Introduction. New York: Routledge.

Qiu S S, Yue W Z, Zhang H et al., 2017. Island ecosystem services value, land-use change, and the National New Area Policy in Zhoushan Archipelago, China. Island Studies Journal, 12(2): 177-197.

Shen J, Wu F L, 2017. The suburb as a space of capital accumulation: The development of new towns in Shanghai, China. Antipode, 49(3): 761-780.

Shields R, 1999. Lefebvre, Love \& Struggle: Spatial Dialectics. London: Routledge.

Smith N, 2010. Uneven Development: Nature, Capital, and the Production of Space. Athens: University of Georgia Press.

Soja E W, 1996. Thirdspace: Journeys to Los Angeles and Other Real-and-Imagined Places. Oxford: Blackwell.

Song Y B, 2005. Influence of new town development on the urban heat island: The case of the Bundang area. Journal of Environmental Sciences, 17(4): 641-645.

Su W Z, Ye G B, Yao S M et al., 2014. Urban land pattern impacts on floods in a new district of China. Sustainability, 6(10): 6488-6508.

Tanabe H, 1978. Problems of the new towns in Japan. Geojournal, 2(1): 39-46.

Wang C H, 2009. Dialectics in multitude: An exploration into/beyond Henri Lefebvre's conceptual triad of production of space. Journal of Geography Science (Taiwan), 55: 1-24. (in Chinese)

Wang Y W, Heath T, 2010. Towards garden city wonderlands: New town planning in 1950s Taiwan. Planning Perspectives, 25(2): 141-169.

Wu F L, Zhang F Z, Webster C, 2013. Informality and the development and demolition of urban villages in the Chinese peri-urban area. Urban Studies, 50(10): 1919-1934.

Xue C Q L, Wang Y, Tsai L, 2013. Building new towns in China: A case study of Zhengdong New District. Cities, 30(3): 223-232.

Yang Z Z, Zhu X C, Moodie D R, 2015. Optimization of land use in a new urban district. Journal of Urban Planning and Development, 141(2): 05014010.

Ye C, Chen M X, Chen R S et al., 2014. Multi-scalar separations: Land use and production of space in Xianlin, a university town in Nanjing, China. Habitat International, 42: 264-272.

Ye C, Chen M X, Duan J J et al., 2017. Uneven development, urbanization and production of space in the middle-scale region based on the case of Jiangsu province, China. Habitat International, 66: 106-116.

Ye C, Liu Z J, Cai W B et al., 2019. Spatial production and governance of urban agglomeration in China 2000-2015: Yangtze River Delta as a case. Sustainability, 11(5): 1343.

Ye C, Ma X Y, Cai Y L et al., 2018. The countryside under multiple high-tension lines: A perspective on the rural construction of Heping Village, Shanghai. Journal of Rural Studies, 62: 53-61.

Ye C, Zhu J J, Li S M et al., 2019. Assessment and analysis of regional economic collaborative development within an urban agglomeration: Yangtze River Delta as a case study. Habitat International, 83: 20-29.

Zhang J X, Wu F L, 2008. Mega-event marketing and urban growth coalitions: A case study of Nanjing Olympic New Town. Town Planning Review, 79(2/3): 209-226.

Zhang Q M, Zeng Y, Deng J S et al., 2017. "Ghost cities" identification using multi-source remote sensing datasets: A case study in Yangtze River Delta. Applied Geography, 80: 112-121.

Zhang T W, 2000. Land market forces and government's role in sprawl: The case of China. Cities, 17(2): $123-135$.

Zhuang L, Ye C, Ma W et al., 2019. Production of space and developmental logic of New Urban Districts in China. Acta Geographica Sinica, 74(8): 1548-1562. (in Chinese)

Zhuang L, Ye C, 2018. Disorder or reorder? The spatial production of State-level New Areas in China. Sustainability, 10(10): 3628 . 